\title{
Synovial lymphocytes and the aetiology of synovitis
}

\author{
Hill Gaston
}

The paramount importance of lymphocytes in the aetiopathogenesis of inflammatory synovitis is an essential article of faith for rheumatologists of the immunological tendency, and this belief underlies a substantial proportion of the current research effort directed against these diseases. Although originally attracted by the B lymphocyte and its ability to make an autoantibody to immunoglobin, most immunologists have transferred loyalty to the T lymphocyte as the major player in the inflamed joint. This idea has been subjected to a number of challenges, however, particularly the suggestion that synovitis is essentially driven by excessive and autonomous monokine production by the macrophage-like synoviocyte population. ${ }^{12}$ This hypothesis concedes that synovial $\mathrm{T}$ cells might have had some long forgotten role in starting off the inflammatory process, but they are thought irrelevant to its maintenance, and to the culmination of synovitis in joint destruction and bony erosion, which is the principal concern of the clinical rheumatologist. The $T$ cells which are such a prominent feature of synovitis are regarded as mere spectators of the monokine driven inflammatory fire, and it is argued that investigation of their properties would be unlikely to tell us anything useful about the pathogenesis of the disease.

However, this view of the role (or lack of it) for $\mathrm{T}$ cells in synovitis may not pay sufficient attention to their usual mode of action. With the exception of cytotoxicity, the physiological effects of $T$ cells are not brought about directly; rather, through the action of specific lymphokines, other cells such as macrophages, B cells, mast cells, fibroblasts, etc are recruited and stimulated to produce inflammatory mediators, antibodies, and other effector functions. Furthermore, one $\mathrm{T}$ cell may recruit many secondary effectors, so that the predominance of non- $\mathrm{T}$ cells or monokines within an inflammatory lesion does not necessarily show that the lesion is not $\mathrm{T}$ cell dependent.

In this article I shall consider what has been learnt from studies of autoimmune diseases, and disease models, which are known to be $T$ cell dependent, and, in particular, what is known about the properties of the immune cells present at the site of disease. It will then be possible to compare these findings with those in inflammatory arthritis, and determine whether the properties of synovial $T$ cells are inconsistent with the notion that antigen specific $\mathrm{T}$ cells are responsible for driving joint inflammation.

\section{Lessons from animal models \\ T CELLS CAN MEDIATE INFLAMMATORY \\ ARTHRITIS}

There is no doubt that antigen specific $T$ cells can be responsible for inducing joint inflammation. The evidence supporting this contention inevitably comes from animal models, as putatively arthritogenic human $T$ cells cannot readily be tested in man. It is a striking characteristic of experimental arthritis that it can be induced not only by various specific antigenic challenges but also by transfer of antigen primed lymphocyte populations, including primed lymph nodes, and in vitro derived $\mathrm{T}$ cell lines and clones. This applies to arthritis induced by bacterial antigens - mycobacteria (Freund's complete adjuvant), streptococcal cell walls, cell walls from gut flora anaerobes ${ }^{3-5}$; by autoantigens cartilage proteoglycan, type II collage ${ }^{6} 7$; and by stimuli such as pristane and synthetic adjuvants where the initiating antigens are not defined. ${ }^{8}{ }^{9}$ Although additional manipulations of the experimental recipient are often required, including mild irradiation, and susceptibility to arthritis varies a great deal in different strains of rodents, these model systems clearly point to the transfer of arthritis by immunocompetent cells. In some cases, such as collagen induced arthritis, there is a role for specific antibody in the transfer of disease, ${ }^{10}$ but the general rule is that disease can only be transferred by lymphoid cells. Induction and transfer of disease both require $\mathrm{T}$ cells (usually CD4, but occasionally CD8 or a mixture of the two subsets) and can be prevented by treatment with $\mathrm{T}$ cell specific monoclonal antibodies directed against cells expressing CD4, the $\alpha / \beta \mathrm{T}$ cell receptor, or even the $T$ cell receptor using particular $V_{\beta}$ genes. ${ }^{11-13}$ In these respects, models of arthritis have characteristics similar to models of other autoimmune diseases, such as experimental allergic encephalomyelitis, thyroiditis, or uveitis, and the spontaneous diabetes which develops in the non-obese diabetic mouse. Although there is argument about the extent to which these models mimic real human diseases such as multiple sclerosis and insulin dependent diabetes mellitus, common features, such as the involvement of major histocompatibility complex (MHC) antigens in disease susceptibility (reviewed in ref 14), and the ability of $\mathrm{T}$ cell specific drugs such as cyclosporin $\mathrm{A}$ to 
modulate disease (as shown in early insulin dependent diabetes mellitus ${ }^{15}$ ), suggest that these models are relevant. Both these features are common to rheumatoid arthritis (RA) and the experimental arthropathies discussed above, so it is scarcely justified to dismiss the information gleaned from studying these models.

T CELL INDEPENDENT INFLAMMATORY

ARTHRITIS CAN ALSO OCCUR

Having emphasised animal models of arthritis in which $\mathrm{T}$ cell mediated responses are critical, it is necessary to recall that there are also experimental models of arthritis in which $\mathrm{T}$ cells are either not involved, or have only a secondary role. Two of the most recently described involve mice made transgenic for either part of the genome of the retrovirus HTLV-I, ${ }^{16}$ or for human tumour necrosis factor $\alpha .{ }^{17}$ In the latter case the joint seems to be particularly sensitive to the effects of constitutive production of tumour necrosis factor $\alpha$. In the former, one of the retroviral genes, Tax, which encodes a trans-acting transcriptional activator, may act to induce cytokine production in the joints - possibly including tumour necrosis factor $\alpha$, though only increased production of interleukin-1 (IL-1) was commented on. In both these models there is lymphocyte and macrophage infiltration of the joint, but it is difficult to imagine that this represents a response to antigen even in the case of the HTLV-I transfected mice as they will be tolerant of their transgenic retroviral proteins. Thus this transgenic model clearly differs from arthritis induced by infection with a retrovirus, such as caprine arthritis-encephalomyelitis virus, where an immune response to infected macrophages is likely to be important. ${ }^{18}$

In addition to transgenic models of arthritis which are $\mathrm{T}$ cell independent, it has also proved possible to induce arthritis in immunodeficient (severe combined immunodeficiency) mice, which lack both $\mathrm{T}$ and $\mathrm{B}$ cells because of an inability to generate either immunoglobin or $\mathrm{T}$ cell receptors. Infection of these mice with Borrelia burgdorferi produced arthritis (and also inflammation of heart and liver), but required a substantial number of organisms $\left(10^{8} /\right.$ mouse $)$ to do so. ${ }^{19}$

WHICH TYPE OF MODEL IS MOST RELEVANT TO HUMAN INFLAMMATORY ARTHRITIS?

Given that there are clearly $T$ cell dependent and $T$ cell independent experimental models of arthritis, the crucial question is, which kind of model best reflects human inflammatory arthritis? One possibility is that the most appropriate model depends on the kind of arthritis: it might be argued that reactive arthritis most closely resembles a $\mathrm{T}$ cell dependent, antigen driven process, whereas RA could be due to retroviral modulation of cytokine production. For the rest of the review, however, I will make the assumption that chronic inflammatory arthritides in which certain MHC genes confer susceptibility (these would include RA, reactive arthritis, sero- negative spondyloarthropathies, and juvenile chronic arthritis) are likely to have broadly similar pathogenetic mechanisms. The easiest explanation for the observed HLA association in these diseases is to postulate that the disease requires a critical $\mathrm{T}$ cell response to an antigen, and that HLA antigens determine whether this response occurs. (A variant hypothesis would be that a normal $\mathrm{T}$ cell response to a critical antigen prevents the development of arthritis, and that certain HLA antigens are associated with an inability of $\mathrm{T}$ cells to respond to that antigen.)

Given this view of the significance of HLA antigens in disease, it is difficult to see why arthritis due to, for instance, retroviral transformation of synovial macrophages should show an HLA association. This is not to play down the likely importance of cells other than $T$ cells in the overall pathogenesis of the disease. Treatments which affect the secondary effector cells whose recruitment is $T$ cell dependent are likely to alleviate disease. As an example, in the non-obese diabetic mouse model of insulin dependent diabetes mellitus, which is clearly $\mathrm{T}$ cell dependent, treatment with antibodies to macrophage complement receptors (CR3) abolishes disease because the final destruction of pancreatic $\beta$ cells involves activated macrophages. ${ }^{20}$ Genetic studies have also shown a role for genes other than those in the MHC in susceptibility to diabetes, possibly including genes controlling responses to IL-1. ${ }^{21}{ }^{22}$ Again these genes act on the $\mathrm{T}$ cell driven process to produce the final disease phenotype. It is likely that similar processes will be at work in joint inflammation.

\section{Lessons from examination of lesional $T$ cells in inflammation}

ANTIGEN SPECIFIC T CELLS AT A SITE OF INFLAMMATION

Studies of lymphocyte trafficking and recirculation have shown that $\mathrm{T}$ lymphocytes are not recruited into tissues on the basis of antigen specificity, and that antigen specific cells represent a very small minority of the lymphoid infiltrate in a delayed-type hypersensitivity response. ${ }^{23}$ Recruitment is now known to depend on the ability of lymphocytes to bind to and migrate through endothelial cells, particularly the specialised cells of high endothelial venules which are found in lymph nodes and also at sites of chronic inflammation such as rheumatoid synovium. ${ }^{24}$ Firm attachment to endothelium, leading to transmigration, is mediated by integrin molecules (LFA-1, VLA-4) whose expression is up-regulated in memory $T$ cells - that is, those which have encountered their specific antigen. ${ }^{25} 26$ It follows that there should be preferential localisation of memory $T$ cells in a site of inflammation, and this has been elegantly demonstrated, at least for an acute inflammatory lesion, by experiments examining $T$ cells migrating into a skin blister challenged with purified protein derivative. ${ }^{27}$ There is no mechanism for excluding particular memory $T$ cells; thus there is no reason to expect that an inflamed joint should consist 
mainly of $\mathrm{T}$ cells specific for one antigen, even if a particular antigenic stimulus within the joint were responsible for driving the inflammatory process.

Two kinds of study in experimental animals point to the same conclusion; in the first the prevalence of antigen specific $T$ cells at the site of disease has been measured, while in the second the migration of $\mathrm{T}$ cells which mediate disease by adoptive transfer has been followed. In experimental allergic encephalomyelitis, limiting dilution assays were used to estimate that $\mathrm{T}$ cells specific for myelin basic protein accounted for $0.04 \%$ of $\mathrm{T}$ cells infiltrating the spinal cord; the prevalence of cells specific for tetanus toxoid was similar if rats were immunised with both myelin basic protein and tetanus toxoid..$^{28}$ Despite this low prevalence of antigen specific cells, $T$ cells capable of transferring disease could be obtained from the spinal cord. In other experiments inducing experimental allergic encephalomyelitis by adoptive transfer, $1 \%$ of the injected $\mathrm{T}$ cells specific for myelin basic protein were shown to migrate into brain and spinal cord where they constituted a small minority of the cells in spinal cord infiltrates. ${ }^{29}$ The effect of this minority has been illustrated by experiments in which the recipients of disease inducing $T$ cells were made severely leucopenic by sublethal irradiation to prevent recruitment of host cells to the inflammatory lesion. ${ }^{30}$ Despite the fact that only scattered lymphocytes were present in the spinal cord these animals still developed paralysis. The infiltrating lymphocytes were presumed to be derived from the donor population and were IL-2 receptor positive. Interestingly, absolute numbers of IL-2 receptor positive $T$ cells were the same in irradiated and normal recipients.

Similar studies have been carried out in experimental arthritis; when fluorescein labelled, mycobacterium specific $T$ cells were transferred into naive rats to induce arthritis they made up only $0.1 \%$ of the lymphoid cells infiltrating the joint. ${ }^{31}$ Other evidence has been obtained in experimental allergic uveitis, in which the target antigen, S-antigen of the photoreceptor layer of the retina, is well defined both biochemically and anatomically. Labelled S-specific $T$ cells injected into the vitreous localised to the photoreceptor layer (non-specific $\mathrm{T}$ cells did not show such localisation), but again they only made up a small proportion of the resulting inflammatory infiltrate. ${ }^{32}$ The conclusion to be drawn from all these studies is that if inflammatory arthritis is driven by antigen specific $T$ cells, these cells are likely to be present as a very small proportion of the total lymphoid infiltrate, even if the presence of antigen within the joint induces some degree of specific accumulation.

MONOKINES IN INFLAMMATORY LESIONS

CAUSED BY T CELLS

If antigen specific $T$ cells are a minority population at the site of inflammation, it would not be surprising if the cytokines they produce were difficult to detect in comparison with those made by the recruited mononuclear cell infiltrate. In a study of naturally occurring delayed-type hypersensitivity reactions in leprosy ('reversal reactions') it was estimated that only $1 \%$ of the $\mathrm{T}$ cells in the lesion were making interferon $\gamma \cdot{ }^{33}$ An even lower proportion $(0.2 \%)$ was found in chronic tuberculous leprosy lesions. $\mathrm{T}$ cells making interferon $\gamma$ in response to myelin basic protein have also been assessed in the cerebrospinal fluid (CSF) of patients with multiple sclerosis; although these were 30 times more prevalent in the CSF of patients with multiple sclerosis than in CSF from patients with meningitis, they accounted for only $0.2-0.6 \%$ of the mononuclear cells. ${ }^{34}$ Examination of cytokine mRNA using polymerase chain reactions in leprosy lesions did show mRNA for $\mathrm{T}$ cell specific lymphokines, but mRNA for monokines was much more abundant. ${ }^{35}$ In active multilple sclerosis IL-1 mRNA was readily detected, but mRNA for either IL-2 or IL-4 was rarely demonstrated. ${ }^{36}$ These results are reminiscent of those seen in RA. ${ }^{37}$ Even in lymph node cells mounting a graft versus host response (a 'pure' $T$ cell disease) the precentage of $T$ cells secreting interferon $\gamma$ was only $3 \%$, with an even lower proportion making other lymphokines. ${ }^{38}$

To prove that the lymphokines produced by a minority $T$ cell population are crucial to the inflammatory lesion, it is critical to determine what happens when the influence of these $T$ cells is removed. There are relatively few data in arthritis. One interesting experiment in man showed that IL-1 production by synovial biopsy fragments in vitro was markedly inhibited in patients who had undergone total lymphoid irradiation (and who had depressed numbers and function of CD4 cells). ${ }^{39}$ The spontaneous production of IL-1 in vitro is a remarkable feature of rheumatoid synovial cells and has been shown to be inhibitable by antibodies to tumour necrosis factor $\alpha^{37}$; however, recent experiments from the same group have suggested that the spontaneous production of these monokines is dependent on the $T$ cell population within the synovium (Brennan F, personal communication).

Experiments on the effect of cytokine specific antibodies and inhibitors on joint inflammation are less informative in terms of indicating the role of $\mathrm{T}$ cells. Many agents which have an effect on late events in the inflammatory response will alleviate arthritis, the most obvious examples being non-steroidal anti-inflammatory drugs. However, more fundamental changes in disease can also be brought about; one recent example is the ability of an inhibitor of angiogenesis both to prevent and treat collagen induced arthritis ${ }^{40}$ (which is also known to be $\mathrm{T}$ cell dependent). Inhibitors of $T$ specific lymphokines may also be unhelpful; gene knockout experiments in mice have demonstrated substantial redundancy in the immune system. For example, even when the IL-2 gene is inactivated there are still normal numbers of thymus and peripheral $T$ cells which might have used growth factors such as IL-4 or IL-7 in their development. ${ }^{41}$ The most convincing exper- 
iments which show $T$ cell dependence of inflammation are those in which antigen specific $T$ cell populations are inhibited by agents such as specific peptides or $T$ cell receptor specific antibodies. These manoeuvres have been successful in the experimental allergic encephalomyelitis model. ${ }^{42} 43$ In human arthritis the lack of data on critical antigens inhibits this kind of study. Identification of the major antigens recognised by synovial $\mathrm{T}$ cells in reactive arthritis ${ }^{44}$ might allow similar approaches in the small proportion of patients whose disease is not self limited.

OLIGOCLONALITY OF T CELL RECEPTOR USAGE IN THE JOINT

In view of the evidence already considered, it would seem unlikely that studies of $\mathrm{T}$ cell receptor usage in the inflamed joint would be able to detect a minority population of antigen specific cells responsible for driving the joint inflammation, even if we were to assume that the same $\mathrm{T}$ cell receptor was always used to recognise a particular $\mathrm{MHC} /$ peptide complex (which is certainly not always the case ${ }^{45}$ ). However, $\mathrm{T}$ cell receptor studies have been informative in experimental models of autoimmunity where the target antigen is defined. In experimental allergic encephalomyelitis, encephalitogenic $T$ cell clones which recognise a myelin basic protein peptide presented by particular class II MHC molecules have been found to use similar $T$ cell receptors ${ }^{43}{ }^{46}$ These findings have recently been extended to multiple sclerosis, though the relevance of immune responses to myelin basic protein in this disease is still controversial. Examination of chronic brain plaques has shown restricted T cell receptor usage. ${ }^{47}$ This was most evident when analysis was confined to DR2 positive patients (Steinman L, personal communication); DR2 restricted T cells specific for myelin basic protein also appear to use a limited set of $\mathrm{T}$ cell receptors. ${ }^{48}$

Despite the absence of candidate antigens in $R A$, several studies of $T$ cell receptor usage have been carried out. Some made the assumption that the critical antigen specific cells in the joint would express the IL-2 receptor and could therefore be selected in vitro by culture with IL-2. Certainly, culture with IL-2 did produce evidence of an oligoclonal population in synovial $\mathrm{T}$ cells, as judged by Southern blotting. ${ }^{49}$ Separate studies found minimal evidence of oligoclonality in unexpanded synovial $\mathrm{T}$ cells, or in cells expanded non-specifically by anti-CD3 and IL-2, whereas synovial tissue $\mathrm{T}$ cells expanded in IL-2 alone did sometimes show oligoclonality. ${ }^{50}$ In the absence of data on the function of these oligoclonal populations it is hard to assess their significance.

The polymerase chain reaction is a much more sensitive way of analysing $\mathrm{T}$ cell receptor usage, but has produced controversial results. In most reports $T$ cell receptor usage in synovial fluid and peripheral blood has been compared, and increased expression of particular $\alpha$ or $\beta$ families has been noted in synovial fluid. This has sometimes been interpreted as suggesting involvement of a superantigen. ${ }^{52}$ Superantigens differ from conventional antigens in that they bind to and stimulate all $\mathrm{T}$ cells which express particular families of $T$ cell receptor; normal antigens only stimulate antigen specific $\mathrm{T}$ cells. Paliard et al noted a loss of $\mathrm{V}_{\beta} 14 \mathrm{~T}$ cells from peripheral blood of patients with RA accompanied by $V_{\beta} 14$ expression in synovial fluid and synovium, and suggested that this might be explained by superantigen stimulation of $\mathrm{V}_{\beta} 14$ cells in the periphery. ${ }^{52}$ Experiments in mice have shown that superantigen stimulation can result in deletion of $T$ cells whose $T$ cell receptors are bound by the superantigen, so a superantigen would account for the loss of peripheral $\mathrm{V}_{\beta} 14 \mathrm{~T}$ cells. If a subgroup of these reacted with a conventional self antigen in the joint, however, they could continue to be stimulated locally. Sequencing $V_{\beta} 14$ chains from synovial fluid showed a small number of dominant clones, consistent with the idea that they were responding to a defined antigen in the joint. In another study the $V_{\beta}$ genes used predominantly in the synovium varied from patient to patient, which does not suggest involvement of a superantigen unless it had a very wide specificity, but again sequencing $\mathrm{T}$ cell receptors from the dominant family present in the joint showed highly related sequences, consistent with recognition of local antigen. ${ }^{54}$ Interestingly, we have recently isolated two clones with identical receptors and antigen specificity on separate occasions from a rheumatoid synovial fluid (Henwood $\mathrm{J}$ et al, unpublished data).

These studies of $T$ cell receptor usage in the joint are still at a relatively early stage and it is still important to define such usage in the normal recognition of particular MHC/peptide complexes by different subjects. Certainly, current data on $T$ cell receptor usage in the joint do not argue convincingly against an important role for synovial $\mathrm{T}$ cells in pathogenesis.

\section{Conclusions}

In the light of the experimental evidence discussed, what can we expect to learn from studying synovial lymphocytes? Firstly, it is still not unreasonable to believe that a critical $\mathrm{T}$ cell population maintains inflammation throughout the time of active disease. Secondly, it is likely that this population will have relatively subtle properties in terms of lymphokine production, not shown by analysis of total lymphokine production in the joint. Thirdly, it is unlikely that the critical cells will be easily disclosed by studies of $T$ cell receptor usage, although, as discussed above, involvement of a superantigen would increase the likelihood of such studies being successful. Lastly, the best way to demonstrate $T$ cell involvement in pathogenesis is to identify critical antigens. In this respect an elucidation of the pathogenesis of reactive arthritis (where there is at least some information on candidate antigens) may be the first stop in the process of unravelling more complex diseases such as rheumatoid arthritis. 
1 Firestein G S, Zvaifler N J. How important are T cells in chronic rheumatoid synovitis? Arthritis Rheum 1990; 33: 768-73.

2 Firestein G S. The immunopathogenesis of rheumatoid arthritis. Curr Opin Rheumatol 1991; 3: 398-406.

3 Holoshitz J, Matitiau A, Cohen I R. Arthritis induced in rat by clones of $\mathrm{T}$ lymphocytes responsive to mycobacteria but not to collagen type II. $\mathcal{F}$ Clin Invest $1984 ; 73: 211-5$.

4 DeJoy Quinn S, Ferguson K M, Sapp T M, Zabriskie J B Oronsky A L, Kerwar S S. Streptococcal cell wall arthritis Passive transfer of disease with a $\mathrm{T}$ cell line and crossreactivity of streptococcal cell wall antigens with Mycobacter

5 Klasen I S, Kool S, Melief M J, et al. Arthritis by autoreactive $\mathrm{T}$ cell lines obtained from rats after injection of intestinal bacterial cell wall fragments. Cell Immuno 1992; 139: 455-67.

6 Mikecz K, Glant T T, Buzas E, Poole A R. Proteoglycaninduced polyarthritis and spondylitis adoptively transferred to naive (non-immunized) $\mathrm{BALB} / \mathrm{c}$ mice Arthritis Rheum 1990; 33: 866-76.

7 Trentham D E, Townes A S, Kang A H. Autoimmunity to type II collagen: an experimental model of arthritis. $\mathcal{F}$ Exp Med 1977; 146: 857-68.

8 Billingham M E J, Carney S, Butler R, Colston M J. A mycobacterial $65-\mathrm{kD}$ heat shock protein induces antigenspecific suppression of adjuvant arthritis but is not itself arthritogenic. $₹$ Exp Med 1990; 171: 339-44.

9 Thompson S J, Rook G A V, Brealey R J, van der Zee R, Elson C J. Autoimmune reactions to heat shock protein in pristane-induced arthritis. Eur f Immunol 1990; 20: 2479-84.

10 Stuart J M, Cremer M A, Townes A S, Kang A H. Type II collagen-induced arthritis in rats: passive transfer with serum and evidence that IgG antibodies can cause arthritis. $f$ Exp Med 1982; 155: 1-6.

11 Ranges G E, Sriram S, Cooper S M. Prevention of type II collagen-induced arthritis by in vivo treatment with antiL3T4. F Exp Med 1985; 162: 1105-10.

12 Yoshino S, Cleland L G. Depletion of alpha/beta T cells by a monoclonal antibody against the alpha/beta $T$ cell receptor suppresses established adjuvant arthritis but no established collagen-induced arthritis in rats. $7 \mathrm{Exp} \mathrm{Med}$ 1992; 175: 907-15.

13 Chiocchia G, Boissier M-C, Fournier C. Therapy against murine collagen-induced arthritis with $\mathrm{T}$ cell receptor $V_{\text {beta }}$-specific antibodies. Eur $\mathcal{F}$ Immunol 1991; 21: 2899-906.

14 Wraith D C, McDevitt H O, Steinman L, Acha-Orbea H. $T$ cell recognition as the target for immune intervention in autoimmune disease. Cell 1989; 57: 709-15.

15 Feutren G, Lapoz L, Assan R, et al. Cyclosporin increase the rate and length of remissions in insulin-dependen diabetes of recent onset. Lancet 1986; ii: 119-23.

16 Iwakura Y, Tosu M, Yoshida E, et al. Induction of inflammatory arthropathy resembling rheumatoid arthritis in mice transgenic for HTLV-1. Science 1991; 253: $1026-8$.

17 Keffer J, Probert L, Cazlaris $\mathrm{H}$, et al. Transgenic mice expressing human tumour necrosis factor: a predictive genetic model of arthritis. EMBO f 1991; 10: 4025-31.

18 Haase A T. Pathogenesis of lentivirus infection. Natur 1986; 322: 130-6.

19 Schaible U E, Kramer M D, Justus J W E, et al. The severe combined immunodeficiency (SCID) mouse: a laboratory model for the analysis of Lyme arthritis and carditis. $\mathcal{F}$ Exp Med 1989; 170: 1427-32.

20 Hutchings P, Rosen H, O'Reilly L, Simpson E, Gordon S, Cooke A. Blockade of adhesion promoting receptor on macrophages prevents transfer of IDDM in NOD mice. Nature 1990; 348: 639-42.

21 Todd J A, Aitman T J, Cornall R J, et al. Genetic analysis of autoimmune type I diabetes mellitus in mice. Nature 1991; 351: 542-7.

22 Cornall R J, Prins J-B, Pressey A, DeLarato N H, Wocker L S, Peterson L B. Type I diabetes in mice is linked to the interleukin-1 receptor and $\mathrm{Lsh} / \mathrm{Ity} / \mathrm{Bcg}$ genes on chromosome 1. Nature 1991; 353: 262-5.

23 McCluskey R T, Benacerraf B, McCluskey J W. Studies on the specificity of the cellular infiltrate in delayed hypersensitivity reactions. F Immunol 1963; 90: 466-77.

24 Stoolman L. Adhesion molecules controlling lymphocyte migration. Cell 1989; 56: 907-10.

25 Sanders M E, Makgoba M W, Shaw S. Human naive and memory $\mathrm{T}$ cells: reinterpretation of helper-inducer and suppressor-inducer subsets. Immunol Today 1988; 9: 195-200.

26 Pitzalis C, Kingsley G H, Haskard D O, Panayi G S. The preferential accumulation of helper-inducer $T$ lymphocytes in inflammatory lesions: evidence for regulation by selective endothelial and homotypic adhesion. Eur f Immunol 1988; 18: 1397-404.

27 Pitzalis C, Kingsley G H, Covelli M, Meliconi R, Markey A, Panayi G S. Selective migration of human helperinducer memory $T$ cell subset: confirmation by in vivo cellular kinetics. Eur f Immunol 1991; 21: 369-76.

28 Cohen J A, Essayan D M, Zweiman B, Lisak R P. Limiting dilution analysis of the frequency of antigen-reactive lymphocytes isolated from the central nervous system of Lewis rats with experimental allergic encephalomyelitis. Cell Immunol 1987; 108: 203-13.

29 Naparstek Y, Ben Nun A, Holoshitz J, et al. T lymphocyte lines producing or vaccinating against autoimmune encephalomyelitis. Functional activation induces peanut agglutinin receptor and accumulation in the brain and thymus of the cells. Eur f Immunol 1983; 13: 418-23.

30 Sedgwick J, Brostoff S, Mason D. Experimental allergic encephalomyelitis in the absence of a classical delayedtype hypersensitivity reaction. F Exp Med 1987; 165: 1058-75.

31 DeJoy Quinn S, Ferguson-Chanowitz K, Oronsky A L, Zabriskie J B, Kerwar S S. Studies on the homing of mycobacterium-sensitized $T$ lymphocytes to the synovium during passive adjuvant arthritis. Cell Immunol

32 Kim M K, Caspi R R, Nussenblatt R B, Kuwabara T, Palestrini A G. Intra-ocular trafficking of lymphocytes in locally induced experimental uveoretinitis. Cell Immunol 1988; 112: 430-6.

33 Cooper C L, Mueller C, Sinchaisri T-A, et al. Analysis of naturally occurring delayed-type hypersensitivity reactions in leprosy by in situ hybridization. $f \operatorname{Exp} M e d$ 1989; 169: 1565-81

34 Olsson T, Zhi W W, Hojebrg B, et al. Autoreactive T lymphocytes in multiple sclerosis determined by antigeninduced secretion of interferon-gamma. $\mathcal{F}$ Clin Invest 1990; 86: 981-5.

35 Yamamura $\mathrm{M}$, Uyemura $\mathrm{K}$, Deans $\mathrm{R} \mathrm{J}$, et al. Defining protective responses to pathogens: cytokine profiles in leprosy lesions. Science 1991; 254: 277-9.

36 Wucherpfennig K W, Newcombe J, Li H, Keddy C, Cuzner $M L$, Hafler D A. T cell receptor $\mathrm{V}_{\text {alpha }}-\mathrm{V}_{\text {beta }}$ repertoire and cytokine gene expression in active multiple sclerosis cytokine gene expression in active mult
lesions. $f$ Exp Med 1992; 175: 993-1002.

37 Brennan F M, Maini R N, Feldman M. TNFalpha - a pivotal role in rheumatoid arthritis? Br f Rheumatol 1992; 31: $293-8$.

38 Troutt A B, Kelso A. Enumeration of lymphokine mRNAcontaining cells in vivo in a murine graft-versus-host reaction using the PCR. Proc Natl Acad Sci USA 1992; 89: $5276-80$.

39 Gaston I S H, Strober S, Gandour D, et al. Dissection of the mechanisms of immune injury in rheumatoid arthritis using total lymphoid irradiation. Arthritis Rheum 1988; 31: $21-30$

40 Peacock D J, Banquerigo M L, Brahn E. Angiogenesis inhibition supresses collagen arthritis. F Exp Med 1992; 175: $1135-8$

41 Schorle H, Holtschke T, Hunig T, Schimpi A, Horak I. Development and function of $T$ cells rendered interleukin-2 deficient by gene targetting. Nature 1991; 352: $621-4$.

42 Wraith D C, Smilek D E, Mitchell D J, Steinman L, $\mathrm{McDevitt} \mathrm{H} \mathrm{O}$. Antigen recognition in autoimmune encephalomyelitis and the potential for peptide-mediated immunotherapy. Cell 1989; 59: 247-55.

43 Acha-Orbea H, Mitchell D J, Timmermann L, et al. Limited heterogeneity of $T$ cell receptors from lymphocytes mediating autoimmune encephalomyelitis allows specific immune intervention. Cell 1988; 54: 263-73.

44 Life P F, Bassey E O E, Gaston J S H. T cell recognition of bacterial heat-shock proteins in inflammatory arthritis. Immunol Rev 1991; 121: 113-35.

45 Boitel B, Ermonval M, Panina-Bordignon P, Mariuzza R A, Lanzavecchia $A$, Acuto $O$. Preferential $V_{\text {bera }}$ gene usage and lack of junctional sequence conservation among human $T$ cell receptors specific for a tetanus toxin-derived peptide: evidence for a dominant role of a germlineencoded $\mathrm{V}$ region in antigen/major histocompatibility complex recognition. $₹$ Exp Med 1992; 175: 765-77.

46 Urban J L, Kumar V, Kono D H, et al. Restricted use of $\mathrm{T}$ cell receptor $\mathrm{V}$ genes in murine autoimmune encephalomyelitis raises possibilities for antibody therapy. Cell 1988; 54: 577-92.

47 Oksenberg J R, Stuart S, Begovich A B, et al. Limited heterogeneity of rearranged $T$ cell receptor $V_{\text {alpha }}$ transcripts in brain of multiple sclerosis patients. Nature 1990; 345: 344-6.

48 Wucherpfennig K W, Ota K, Endo N, et al. Shared human $T$ cell receptor $\mathrm{V}_{\text {beta }}$ usage to immunodominant regions of myelin basic protein. Science 1990; 248: 1016-9.

49 Stamenkovic I, Stegagno M, Wright K A, et al. Clonal dominance among $T$ lymphocyte infiltrates in arthritis. Proc Natl Acad Sci USA 1988; 85: 1179-83.

50 van Laar J M, Miltenberg A M M, Verdonk M-J A, et al. Lack of T-cell oligoclonality in enzyme digested synovial tissue and in synovial fluid in most patients with rheumatoid arthritis. Clin Exp Immunol 1991; 83: 352-8.

51 Cooper S M, Dier D L, Roessner K D, Budd R C, Nicklas $\mathrm{J}$ A. Diversity of rheumatoid synovial tissue $\mathrm{T}$ cells by $\mathrm{T}$ cell receptor analysis. Oligoclonal expansion in interleukin-2 responsive cells. Arthritis Rheum 1991; 34: 537-46.

52 Paliard X, West S G, Lafferty J, et al. Evidence for the effects of a superantigen in rheumatoid arthritis. Science 1991; 253: $325-9$.

53 Howell M D, Diveley J P, Lundeen K A, et al. Limited T 2 receptor-positive synovial $T$ cells suggests a role for 2 receptor-positive synovial $T$ cells suggests a role for superantigen in rheumato

54 Lunardi C, Marguerie C, So A K L. Evidence for restricted $\mathrm{T}$-cell receptor beta-chain heterogeneity and clonal expression in rheumatoid synovitis. Br f Rheumatol 1992; 31 (suppl 2): 104s. 